\title{
The history of very: the directionality of functional shift and (inter)subjectification
}

DOI:

$10.1017 / \mathrm{S} 1360674315000428$

\section{Document Version}

Accepted author manuscript

Link to publication record in Manchester Research Explorer

\section{Citation for published version (APA):}

Breban, T., \& Davidse, K. (2016). The history of very: the directionality of functional shift and (inter)subjectification. English Language and Linguistics, 20(2), 221-249. https://doi.org/10.1017/S1360674315000428

\section{Published in:}

English Language and Linguistics

\section{Citing this paper}

Please note that where the full-text provided on Manchester Research Explorer is the Author Accepted Manuscript or Proof version this may differ from the final Published version. If citing, it is advised that you check and use the publisher's definitive version.

\section{General rights}

Copyright and moral rights for the publications made accessible in the Research Explorer are retained by the authors and/or other copyright owners and it is a condition of accessing publications that users recognise and abide by the legal requirements associated with these rights.

\section{Takedown policy}

If you believe that this document breaches copyright please refer to the University of Manchester's Takedown Procedures [http://man.ac.uk/04Y6Bo] or contact uml.scholarlycommunications@manchester.ac.uk providing relevant details, so we can investigate your claim.

\section{OPEN ACCESS}


The history of very: the directionality of functional shift and (inter)subjectification ${ }^{1}$ TINE BREBAN

The University of Manchester and University of Leuven

KRISTIN DAVIDSE

University of Leuven

\footnotetext{
${ }^{1}$ We sincerely thank the two anonymous referees for their very generous and helpful comments, which helped us re-define "our problem space". We also thank Wim van der Wurff, who started us off on the revision, and Laurel Brinton, who helped us complete the revision cycle. Tine Breban worked on this paper at the Freie Universität Berlin, while she was funded as a post-doctoral fellow by the Alexander von Humboldt Stiftung. She thanks Ferdinand von Mengden and all colleagues at the FU Berlin for their hospitality. Kristin Davidse was able to work on this paper thanks to the sabbatical leave grant K8.017.12N from the Research Fund Flanders FWO. This joint research was further supported by the GOA-project 12/007, “The multiple functional load of grammatical signs”, awarded by the Research Council of the University of Leuven.
} 
On the basis of extensive corpus analysis, we reconstruct the history of very and the paths of change along which it acquired new meanings. We propose an analytical model that, firstly, assigns general semantic functions to the (sub)modifier relations in the English noun phrase and, secondly, identifies subsenses of these functions on the basis of collocational, semantic and pragmatic distinctions observed in different contexts. Thus, we arrive at a comprehensive description of the various (sub)modifier relations in which very has functioned in its history. Having been borrowed into English as part of fixed collocations such as very Ihus ('the true Jesus'), and croice verra ('the true cross'), very successively acquired the functions of descriptive modifier, nounintensifier, focus marker, adjective-intensifier, classifier, postdeterminer-intensifier, quantifier-intensifier and postdeterminer. This description allows us to interpret the history of very as a paradigm case of progressive grammaticalization and (inter)subjectification involving leftward movement in the English NP (Adamson 2000). Our analytical model allows us to capture finer mechanisms of change such as collocational extension, pragmatically-driven host class expansion, invited inferences and analogy. 


\section{INTRODUCTION}

Through its history, very has occurred in an exceptionally great number of modifier and submodifier functions in the English noun phrase (NP). Its original lexical meaning 'true' survives only in archaic phrases, such as very god from very god. As a grammaticalized intensifier, very can intensify not only nouns, e.g. the very beginning, but also adjectives, e.g. a very clean bowl, adverbs, e.g. very curiously figured bodies, determiners, e.g. this very day, quantifiers, e.g. very many things and postdeterminers, e.g. the very same day. It can also function as a focus marker as in the deadly cocktail of drugs, guns and Aids currently sweeping inner city America is threatening the very existence of Afro-Americans, where very marks inclusive focus ('even').

Syntheses of the many meanings of very have so far been attempted mainly from a lexico-semantic perspective, which may generalize over grammatical classes. Brugmann's (1984) synchronic study thus groups together meanings of adjectival and adverbial very. For instance, her 'extreme' sense subsumes uses such as the very (adj.) back of the room and the very (adv.) best croissants I have ever eaten (Brugmann 1984: 21-2). Likewise, her 'precise' sense includes both the very (adj.) person I've been waiting to see and the very (adv.) same dress I tried on last week (Brugmann 1984: 212). The diachronic entry in the Oxford English Dictionary makes a principled distinction between adjectival and adverbial very but groups together different modifier classes for some subsenses, e.g. the meaning under B. adv. 2, "[i]n a high degree or measure", subsumes modification of both adjectives, My father..ys a verye old man (?1589, OED) and quantifiers, e.g. there remaine but very few ruines (1600, OED). Whilst such an account may be justified from a lexico-semantic point of view, it does not interpret the 
structural and scopal differences between very as a modifier of adjectives and quantifiers, as illustrated by NPs that contain the two, e.g. very few very local places.

In Adamson's grammar-based (2000) approach to change affecting adjectives in the English NP, it is precisely change of structural position that is correlated with semantic change. She follows Teyssier (1968) in dividing the possible positions of prenominal adjectives from left to right into the three zones of (1) identifiers and intensifiers, (2) descriptive adjectives, and (3) classifying adjectives. Adamson ventures that change typically starts from the descriptive uses, which occur in the central zone, with reanalyzed uses moving to more leftward or rightward positions. The main path of change involves leftward movement and is associated with a shift from denotational to speaker-related meaning, i.e. subjectification, and from an independent lexical use to that of a grammatical operator, i.e. grammaticalization. One such change is from descriptive modifier to intensifier, which Adamson (2000: 47-55) illustrates with the case of lovely. Shifting from its original descriptive meaning 'amiable, physically beautiful', lovely came to be used in a position leftward of the descriptive adjective, as in lovely long legs, where it functions as an intensifying submodifier of the descriptive modifier long. Adamson (2000: 59) discusses another change involving - further leftward movement, viz. from intensifier to identifier, which both have subjective and grammatical meaning, and which she illustrates with different uses of mere such as $a$ mere pittance versus faint at the mere mention of deep muscle injections ${ }^{2}$ (WB). Changes in which adjectives move rightward from their central descriptive uses, then, form the second, more minor, path of change. The adjective enters into an entrenched collocational combination with the head noun, to which it adds 'classifying'

\footnotetext{
${ }^{2}$ We analyse the latter use not as identifying but as focus marking (see Section 4.4).
} 
denotational meaning, which is more objective than the original descriptive use. Adamson (2000: 60) illustrates this path of lexicalization and desubjectification with the adjective criminal, which loses its meaning of speaker-based assessment when it comes to be used in collocations such as criminal law. The changes that led to the intensifying and grammatical uses of very clearly involved some form of leftward movement, but this development has not been studied in depth and neither has the possible occurrence of classifying uses of very been looked into.

There is, to our knowledge, no grammar-based study of very yet, in which the different (sub)modifier relations in which it can figure are coupled to functional distinctions. Nor has the history of very, in spite of the unique scope of its changes, been related to Adamson's comprehensive hypothesis of change in the English NP. We set out to fill these gaps with this study.

In Section 2 we describe all the distinct (sub)modifier relations in which adjectival and adverbial very participate, explicating the differences in structure and scope that remain more implicit in Adamson (2000). Our model differs from Adamson's in that grammatical categories are not viewed as primitives. Rather, the overarching construction defines its elements of structure, which in turn determine the grammatical classes realizing them (Halliday 1963, Croft 2000). In Section 3 we motivate the data we collected and analyzed to realize our research aims. In Section 4 we identify the main grammatical functions very has fulfilled throughout its history, and the finer subsenses that can be distinguished on the basis of collocational, semantic and pragmatic distinctions. This allows us to formulate generalizations in Section 5. Firstly, we relate the functional shifts of very to Adamson's (2000) hypotheses. In addition, we 
assess our analytical model of the English NP with regard to its potential for precisely reconstructing language change.

\section{A FUNCTIONAL-STRUCTURAL MODEL OF ENGLISH NP STRUCTURE}

In this section we set out our model of the basic functions coded by the different (sub)modifier relations in English NP structure. Theoretically, we adhere to the cognitive-functional assumption that a construction's meaning is coded by its lexicogrammatical form (e.g. Langacker 1987, 1991; Halliday 1994; McGregor 1997; Croft 2000). In particular, we adhere to the view that constructions are composite structures, some of whose components are transparently assembled, whilst others are 'only partially discernible (or even indiscernible) within the composite whole' (Langacker 1999: 152). In the pairing of form and meaning, it is the syntagmatic structural combinatorics that are crucial to the meaning of the construction, but paradigmatic relations are fundamental to the identification of the structural components (McGregor 1997: 47). Structural analysis is concerned with 'the order in which component structures are successively combined to form progressively more elaborate composite structures' (Langacker 1987: 310). The order of assembly that analysts have to identify is the one that accounts best for the composite semantics of the structure, as conceptual dependencies between elements are 'largely responsible, in the final analysis, for their combinatory behaviour' (Langacker 1987: 305).

Descriptively, i.e. with regard to the semantic functions assigned to the (sub)modifiers, our model is indebted most to the Hallidayan tradition (Halliday \& Hasan 1976, Dixon 1982, Halliday 1994, McGregor 1997, Bache \& Davidsen-Nielsen 1997), in which, however, the focus marking function was not singled out for separate 
treatment. Earlier versions of our description can be found in, amongst others, Vandewinkel \& Davidse (2008), Breban (2010a, 2010b) and Ghesquière \& Davidse (2016).

In English NPs that do not consist of just a pronoun or proper name, the other elements besides the head are typically (sub)modifiers, i.e. conceptually dependent elements (Langacker 1987: 235-6, 309-10). The basic grammatical functions in the NP are coded by distinct modifier-head and submodifier-modifier relations. For each, the precise units involved in the binary relation and its semantic computation will be discussed.

The HEAD of an NP is typically a common noun, but can also be a member of another class, for instance an adjective, coerced into a common noun reading, e.g. the poor. The head designates the general type of entity, of which the whole NP depicts an instance (Langacker 1991: 144ff.).

The modifier that integrates first with the head is the CLASSIFIER (Halliday 1994: 184-5), realized either by an adjective (e.g. electric train) or a noun (e.g. steam train). Classifiers are the most direct modifiers of the head, occurring immediately to its left, e.g. legal successor, or right, e.g. heir apparent. They cannot be separated from the head by elements with other functions such as descriptive modification: *a legal unscrupulous successor. Semantically, the resulting unit is a composite type description, in which the classifier 'restricts the denotative scope' of the head noun (Adamson 2000: 57). Successive classifiers can be interpreted only as recursively restrictive: model electric train is an electric train, but of model size.

Next in the assembly of NP structure comes the DESCRIPTIVE MODIFIER, which modifies the head and any classifiers it may have. It differs from the classifier in that it 
does not restrict the general type denoted by the head, but ascribes a property to the instance referred to. The descriptive modifier is typically realized by an adjective, e.g. $a$ brave man. Syntactically, it behaves very differently from the classifier: its premodifier use typically alternates with descriptive predicate use, e.g. That man is brave. It is precisely because the adjective ascribes a property or state to the instance referred to that it can do this either by predication of a subject NP or by premodification of a head noun (Bolinger 1967). Successive descriptive modifiers - unlike classifiers - do not necessarily receive a recursively restrictive interpretation (Dixon 1982: 25): both $a$ clever brave man and a brave clever man ascribe the independent properties of cleverness and braveness to the referent. If two descriptive modifiers are interpreted restrictively, this is due to contextual factors, as in We need KIND strict teachers, not despotic ones, where the contrastive stress on kind sets off the subset of kind strict teachers against despotic ones. ${ }^{3}$

The assembly of the NP continues with the NOUN-INTENSIFIER, which applies to all the relevant gradable properties of the referent, expressed by the head and any lexical pre- or postmodifiers it may have. For instance, pure in pure hard work intensifies the notions of 'labouring intensively'. Semantically, the modification by a noun-intensifier is of a different nature than the modification by descriptive or classifying modifiers. The latter add elements to the description of the referent, and are, in this respect, processed compositionally. Noun-intensifiers convey subjective speaker-stance vis-à-vis the NP referent and their meaning 'overlays' and moulds all the descriptive material in their scope (McGregor 1997: 67). McGregor (1997) argues that this is a different type of modification relation, which he calls 'interpersonal modification' (1997: 236). The

\footnotetext{
${ }^{3}$ We thank our first anonymous referee for pointing this out.
} 
interpersonal modifier qualitatively changes the descriptive meaning of the unit it relates to, in this case modifying the degree of that unit's gradable features.

Descriptive adjectival modifiers may be submodified by ADJECTIVE-INTENSIFIERS that typically precede them, e.g. a very brave man, that man is very brave. Such intensifying submodifiers are structurally integrated with the descriptive adjective. Similar to noun-intensifiers, they are interpersonal modifiers, which change the degree of the qualities designated by the adjectives in their scope. When construed adverbially, quality descriptions can add characterizations such as manner or cause to an action or event. These can also pattern with intensifying submodifiers (ADVERB-INTENSIFIERS), which change the degree of the adverbial quality, e.g. very curiously figured bodies, he fought very bravely.

Next in the assembly of the NP come FOCUS MARKERS, which we argue are different from the other grammatical functions in terms of their structural position and scope. The focus marker occurs in a more leftward position than the noun-intensifier, as shown by an example like (1), in which - admittedly exceptionally - the focus marker mere is first followed by the noun-intensifier utter and then by the lexical part of the NP, silence. Focus markers have variable scopal domains, e.g. the whole NP referent in (1), the lexical description leader of the Conservative opposition in (2), and the quantifier in (3).

(1) The mere utter silence was inwardly driving Arthur insane (charmingrp.com/archive/index.php?thread-3415).

(2) Mrs Thatcher was mere leader of the Conservative opposition at the time (WB) 
(3) ... you can imagine how hard it proved to cram 12 whole quatrains into a mere four hours. (WB)

We propose to view focus markers as interpersonal modifiers by which the speaker situates the focus value (the scoped over material) in relation to alternative (implied) values. In McGregor's terms (1997: 211), their semantic function is rhetorical: they 'indicat[e] how the unit fits into the framework of knowledge and expectations relevant to the interaction'. As focus markers 'crucially involve SP/W's [speaker/writer's] attention to $\mathrm{AD} / \mathrm{R}$ [addressee/reader] as a participant in the speech event' (Traugott \& Dasher 2002: 22), we hold that their meaning is intersubjective.

Finally, the DETERMINERS, either simple (e.g. the, this) or complex (another, the same), combine with the rest of the NP, forming the last layer of structural integration. They are the most grammatical and semantically most abstract elements in the NP (Langacker 2002: 9-13). We view determiners as interpersonal modifiers, which semantically have the whole nominal referent in their scope: by his/her choice of determiner the speaker assigns the 'cognitive status' to the referent which will allow the hearer to track that referent in the discourse (Gundel \& al. 1993). Breban (2010a: 11517) has argued that determiners convey intersubjective meaning because they are ‘devices by which speakers take responsibility for success in communication' and seek to meet the hearer's attempts 'to integrate new information with information that is already accessible' (Blakemore 1990: 364, quoted in Traugott 1995: 45). Determiners subsume both identifiers, such as the articles and demonstratives, and quantifiers, e.g. three, many, every (see Davidse 2004). When a determiner is complex, it consists of multiple elements which function as a single unit (see Breban 2010c), e.g. the same, 
such $a$. We use the terms PRE- AND POSTDETERMINERS to refer to same and such respectively. Pre- and post-determiners expresses secondary identifying or quantifying information.

Determiners and postdeterminers may themselves be submodified, as in very many good things, the very same man. To label the meaning of these SUBMODIFIERS OF DETERMINERS we will use the general term 'intensifier'. When we examine these uses in more detail in Sections 4.7 and 4.8 below, we will elucidate their semantics more precisely. They are all instances of modifiers that mould the meaning of the unit in their scope. For instance, submodifiers of quantifiers, e.g. very many, change the quantity referred to.

In this section we have surveyed the NP-functions coded by different (sub)modifier relations which in Section 4 we will show very to have been associated with in its history. Figure 1 visualizes these modifier relations within the English NP. Following McGregor (1997), dependency relations between units whose meanings are assembled compositionally are visualized by arrows (1997: 177), but interpersonal modifiers are visualized by boxed representations, with the interpersonal modifier enclosing the unit that it scopes over (1997: 64-70).

Figure 1. Main dependency relations in the English NP

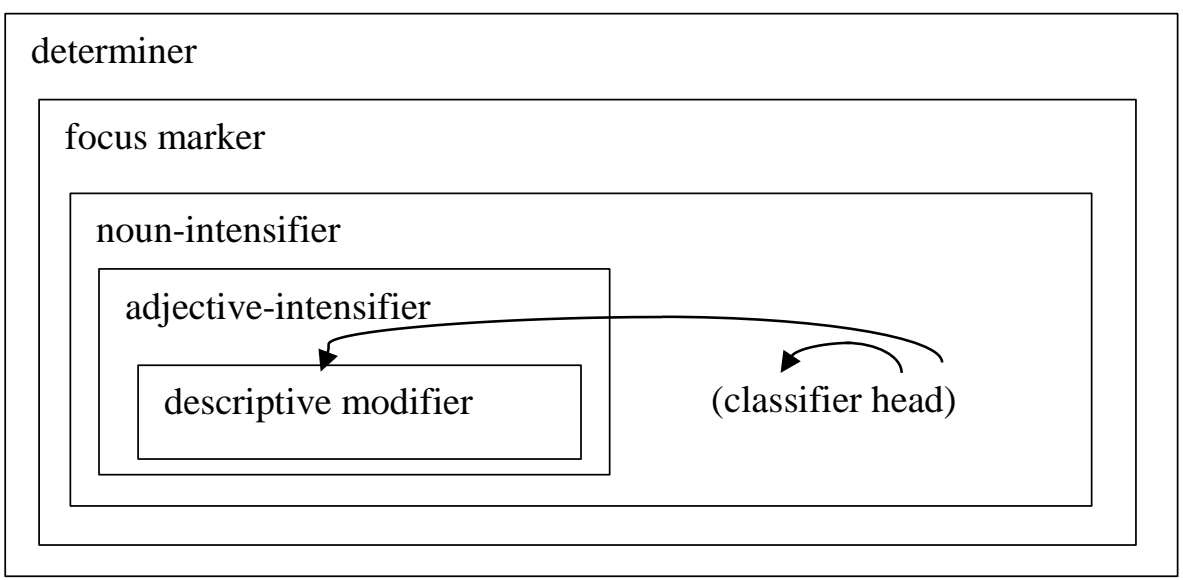




\section{CORPUS DATA AND ANALYSIS}

Since the Oxford English Dictionary puts the first occurrence of the adjective very at $c 1250$, it was necessary to collect diachronic data from Middle English on. We extracted all instances of very found in the Penn-Helsinki Parsed Corpus of Middle English (PPCME2), including in our query the different spellings very/verrey/verray/veray/verry/veri/verrai/verraye/verrei/verey. This extraction yielded 218 instances all told, which are divided as follows over the periods 1250-1350: 1, 1350-1420: 158 and 1420-1500: 59. Because this provided us with too few data for Middle English, we supplemented the PPCME2-data with all the Middle English examples of very as adjective and adverb occurring as citations in the Oxford English Dictionary, which added 166 more examples. OED data do not allow one to track the relative proportions of the various uses throughout different time periods, but the OED entries are reputed for picking up early variants of all the lexico-grammatical patterns associated with a lexical item ${ }^{4}$. Therefore they are crucial to our reconstruction of the chronology in which the functions of very emerged.

In the Modern and Present-Day English corpora we consulted, very is extremely frequent, with 2,536 hits in the Penn-Helsinki Parsed Corpus of Early Modern English (PPCEME), 70,700 in the Corpus of Late Modern English Texts (CLMET3.0), and 117,868 in the British written subcorpora of WordbanksOnline (WB). Therefore, we worked with random samples, which we analyzed in terms of grammatical, collocational, semantic and pragmatic features. From the PPCEME, we extracted samples of 200 tokens for the 70 year periods 1500-1570, 1570-1640, and 1640-1710.

\footnotetext{
${ }^{4}$ For almost all the functions of very, the OED citations contained earlier attestations than the corpora.
} 
From the CLMET, we likewise extracted random samples of 200 tokens for the periods 1710-1780, 1780-1850, 1850-1920. Finally, we compiled a random set of 200 tokens for Present-day English from WordbanksOnline (WB), which covers the period 1995present. These samples allowed us to assess the relative proportions of the grammatical functions in each period, and to examine how they developed over the various periods.

Each instance of very was analyzed independently by the two authors of this paper in terms of its function in the NP (for recognition criteria, see Sections 2 and 4). The analyses were combined into an inter-author agreed final analysis. For illustrative purposes, the odd example will also be cited from the LEON (Leuven English Old to New) corpus and the Middle English Dictionary (MED).

\section{THE DIFFERENT (HISTORICAL) FUNCTIONS OF VERY}

In this section, we discuss all the functions very has fulfilled through its history: fixed collocate (4.1), descriptive modifier (4.2), noun-intensifier (4.3), focus marker (4.4), adjective/adverb-intensifier (4.5), classifier (4.6), postdeterminer-intensifier (4.7), quantifier-intensifier (4.8), and postdeterminer (4.9). The order of presentation corresponds roughly to the order in which the functions emerged. Table 1 represents the absolute and relative frequencies of these functions in our corpus-based datasets for the periods Late Middle English (LME), Early Modern English (EModE), Late Modern English (LModE) and Present-day English (PDE). We list examples in which very can be assigned two functions separately. These examples are treated as BRIDGING CONTEXTS (Evans \& Wilkins 2000), i.e. examples in which two functional analyses are plausible and supported by contextual elements, and which are as such indicative of ongoing change involving these functions (see also Breban 2010a: 105-106). We will 
refer to Table 1 for the development of the relative frequencies through time. Table 2 represents the absolute frequencies of the semantic functions of very attested in the OED citations for Late Middle English, split up into periods of 50 years. We will refer to the findings of both Tables 1 and 2 when we date the emergence of the functions in Late Middle English, and chart their early developments in this period in detail.

Table 1. Absolute and relative frequencies of the functions of very in ME, EModE,

LModE and PDE in the corpus-based datasets

\begin{tabular}{|c|c|c|c|c|c|c|c|c|}
\hline & \multicolumn{2}{|c|}{$\begin{array}{l}\text { LME } \\
(1250-1500)\end{array}$} & \multicolumn{2}{|c|}{$\begin{array}{l}\text { EModE } \\
(1500-1710)\end{array}$} & \multicolumn{2}{|c|}{$\begin{array}{l}\text { LModE } \\
(1710-1920)\end{array}$} & \multicolumn{2}{|c|}{$\begin{array}{l}\text { PDE } \\
(1995-)\end{array}$} \\
\hline fixed collocate & 54 & $24.5 \%$ & 0 & 0 & 0 & 0 & 0 & 0 \\
\hline descriptive modifier & 119 & $54.5 \%$ & 10 & $1.65 \%$ & 0 & 0 & 0 & 0 \\
\hline descriptive predicate & 3 & $2 \%$ & 0 & 0 & 0 & 0 & 0 & 0 \\
\hline noun-intensifier & 16 & $7 \%$ & 39 & $6.5 \%$ & 23 & $4 \%$ & 8 & $4 \%$ \\
\hline focus marker & 4 & $1.5 \%$ & 27 & $4.5 \%$ & 97 & $15.8 \%$ & 6 & $3 \%$ \\
\hline adjective/adverb-intensifier & 12 & $6.5 \%$ & 475 & $79.15 \%$ & 395 & $66 \%$ & 173 & $86.5 \%$ \\
\hline postdeterminer & 0 & 0 & 8 & $1.35 \%$ & 19 & $3.2 \%$ & 3 & $1.5 \%$ \\
\hline postdeterminer-intensifier & 0 & 0 & 31 & $5.15 \%$ & 10 & $1.6 \%$ & 0 & \\
\hline intensifier of quantifier & 0 & 0 & 2 & $0.35 \%$ & 52 & $8.7 \%$ & 9 & $4.5 \%$ \\
\hline classifier & 0 & 0 & 2 & $0.35 \%$ & 0 & 0 & 0 & 0 \\
\hline $\begin{array}{l}\text { descriptive modifier/noun- } \\
\text { intensifier }\end{array}$ & 4 & $1.5 \%$ & 0 & 0 & 0 & 0 & 0 & 0 \\
\hline $\begin{array}{l}\text { noun-intensifier/focus } \\
\text { marker }\end{array}$ & 5 & $2 \%$ & 0 & 0 & 1 & $0.2 \%$ & 0 & 0 \\
\hline $\begin{array}{l}\text { descriptive } \\
\text { modifier/adjective-intensifier }\end{array}$ & 1 & $0.5 \%$ & 2 & $0.35 \%$ & 0 & 0 & 0 & 0 \\
\hline
\end{tabular}




\begin{tabular}{|l|l|l|l|l|l|l|l|l|}
\hline $\begin{array}{l}\text { adjective-intensifier/noun- } \\
\text { intensifier }\end{array}$ & 0 & 0 & 3 & $0.5 \%$ & 0 & 0 & 0 & 0 \\
\hline focus marker/postdeterminer & 0 & 0 & 1 & $0.15 \%$ & 3 & $0.5 \%$ & 1 & 0.5 \\
\hline Total & $\mathbf{2 1 8}$ & $100 \%$ & $\mathbf{6 0 0}$ & $100 \%$ & $\mathbf{6 0 0}$ & $100 \%$ & $\mathbf{2 0 0}$ & $100 \%$ \\
\hline
\end{tabular}

Table 2. Absolute frequencies of the functions of very in ME in the OED citations

\begin{tabular}{|l|l|l|l|l|l|l|}
\hline & $1250-$ & $1300-$ & $1350-$ & $1400-$ & $1450-$ & $1250-$ \\
& 1300 & 1350 & 1400 & 1450 & 1500 & 1500 \\
\hline fixed collocate & 2 & 1 & 7 & 5 & 20 & 35 \\
\hline descriptive modifier & - & 1 & 10 & 19 & 46 & 76 \\
\hline descriptive predicate & - & 1 & 1 & 2 & - & 4 \\
\hline noun-intensifier & - & - & 2 & 6 & 6 & 14 \\
\hline focus marker & - & - & 2 & 2 & 5 & 9 \\
\hline adjective/adverb-intensifier & - & - & - & - & 3 & 3 \\
\hline postdeterminer & - & - & - & - & 1 & 1 \\
\hline postdeterminer-intensifier & - & - & - & - & 1 & 1 \\
\hline intensifier of quantifier & - & - & - & - & 1 & 1 \\
\hline classifier & - & - & - & - & 1 & 1 \\
\hline fixed collocate/noun-intensifier & - & - & 1 & - & 1 & 2 \\
\hline descriptive modifier/noun-intensifier & - & - & 1 & 3 & - & 4 \\
\hline lexical adjunct & - & - & 1 & - & - & 1 \\
\hline modal qualifier of adjective/predicate & - & - & 1 & - & 2 & 3 \\
\hline descriptive modifier/adjective- & - & - & 1 & 3 & 3 & 7 \\
\hline descriptive modifier/focus marker & - & - & - & - & 1 & 1 \\
\hline
\end{tabular}




\begin{tabular}{|l|l|l|l|l|l|l|}
\hline fixed collocate/descriptive modifier & - & - & - & - & 3 & 3 \\
\hline Total & $\mathbf{2}$ & $\mathbf{3}$ & $\mathbf{2 7}$ & $\mathbf{4 0}$ & $\mathbf{9 4}$ & $\mathbf{1 6 6}$ \\
\hline
\end{tabular}

\subsection{Very as fixed collocate}

Very goes back to Latin verus 'true', and was borrowed from Old French in the AngloNorman period, beginning to be attested in English from 1250-1300. The earliest attestations in the OED citations pertain to central notions of the Christian faith, such as warrai man and godd warrai ('true man and true god') (OED, c1250) in (4), warrai scrifte ('true scripture') (OED, 1300), Cryst Iesus very god and man is ('Christ Jesus is true god and true man') (OED, 1398), croice verra ('the true cross') (OED, c1480), very Ihus ('the true Jesus') (PPCME2). Used as it is with both proper names and common nouns, very is non-gradable and does not occur in predicative position: *the rather very/true cross, the cross is very/true. These expressions were all well entrenched in Latin too, and we suggest, therefore, that they entered English as calqued fixed collocations, in which very could occur either to the left (warrai man) or right (godd warrai) of the noun it accompanied. They are clear instances of the earliest meaning documented in the OED, very A. adj. I.1, viz. '[r]eally or truly entitled to the name or designation'. Very is not used as a classifier here as it does not compose a complex type with the noun it co-occurs with, producing a subtype in a taxonomy. Very is not used as a descriptive modifier either: it does not ascribe a quality, e.g. of loyalty, to the instance referred to, as in your very Servant (OED 1676). Rather, the meaning of very relates non-compositionally to the name or common noun in its scope, indicating that these are the correct names, titles or categorizations for the referents in question. 
(4) A clude ('cloud')..bar him vp..Warrai ('very') man and godd warrai. (OED c1250, Cursor Mundi)

In sum, very came into English as a fixed collocate in a limited set of entrenched expressions. They accounted for a quarter of the data in LME, after which they disappeared (see Table 1 above).

\subsection{Very as descriptive modifier}

A crucial step in the development of very came when it detached itself from the fixed collocations by which it had entered English. From commenting on the match between the referent and the head noun, it acquired the ability to designate itself a quality of the referent. That is, it came to function as a descriptive modifier which ascribes properties to the nominal referent such as truthfulness (5), preciseness (6), faithfulness or loyalty (7), legal validity (8), genuineness $(9,10)$, and several others (OED, very A adj. I, MED, verrei), attested from around 1330 on. Semantic entailment may have played a role in this development: stressing the entitlement of different types of referents to their categorizations entails that they have different qualities, such as proven authenticity for relics, e.g. zif pe relikes verray were (OED, 1329) and legal paternity for sons, e.g. my very sonne Esau (OED, 1381). From expressing the match between name and referent, very came to designate a distinct property. These semantic differentiations and extensions of very came about in its spread to different sets of nominal collocates: truthfulness applied to spoken or written messages, preciseness to times, places and (financial) value, faithfulness to partners in a relationship of marriage, friendship or service, and legal validity to rights and legal relationships. Collocationally, very thus 
developed from being part of fixed expressions to being associated, in different subsenses, with different lexical sets. Very occurred with such meanings both in predicative position, e.g. (5), and as a modifier in the NP, e.g. (6)-(10).

(5) Pese wurdes ('words') are verry and clere; (OED 1303, Manning)

(6) Horses will perceive aforehand the very time of the fight (OED 1657, Trapp)

(7) Sir, sir, your very Servant; I was afraid you had forgotten me. (OED 1676, Wycherley)

(8) ..youre auncien enheritaunce, verray right and title in youre duchies of Gascoigne and Guien. (OED 1475, Bk. Noblesse)

(9) It is harde and gret difficulte to knowe bitwen pe verry precious stones and fals (OED $a 1398$, Trevisa)

(10) Ech lyuyng ('living') man is verier..ymage of Crist..than is eny vnquyk ('lifeless') stok (OED c1449, Pecock)

Most of the descriptive modifier meanings of very tend to be bounded, that is, they describe properties that either do or do not apply, such as 'true', 'legally valid' and 'genuine' (Bolinger 1967; Paradis 2000, 2001). However, we also find examples which impose a marked unbounded construal on a sense such as 'genuine', as in (10). The property is then conceptualized as a degree, sanctioning the use of the degrees of comparison.

Structurally, the shift of very from fixed collocate to descriptive modifier involved its coming to function as a distinct, more leftward dependent of the head. As shown by 
(9), descriptive very can modify composite designations such as the classifier-head combination precious stones.

In our LME data set, the descriptive modifier uses account for $54.5 \%$, as shown in Table 1 , with the predicative uses forming a minority of $2 \%$. The descriptive modifier function dropped dramatically to barely $1.65 \%$ in EModE and is no longer attested in the LModE and PDE datasets.

\subsection{Very as noun-intensifier}

Less than a century after the emergence of the descriptive modifier function, very acquired the function of noun-intensifier (first OED attestation 1384). In our data this new function of very appears in two specific collocational contexts, which are treated as separate senses by the OED (very A. adj. I. $3 a$ and $4 b$ ): with nouns referring to truth, such as sooth (OED, sooth $\mathrm{n}$.) in (11), and with nouns describing persons such as fole in $(12) .^{5}$

(11) This is a verray sooth ('truth') with outen ('without') glose ('gloss'). (OED c1386, Chaucer)

(12) Thow ('You') thynkist ('think') in thyn wit..That he nys but ('is not but', 'is only') a verray propre fole. (OED 1384, Chaucer)

\footnotetext{
${ }^{5}$ In example (12) we find two intensifiers, very proper, which was and is not uncommon, as illustrated by Pure dead big superstars like the Wheel of Fortune Prize Guy wouldn't do breakfast in my local (WB), where both pure and dead are intensifiers.
} 
The first pattern is restricted to two fixed phrases, the very truth and the very sooth, which are quite frequent in the LME data (MED, verrei, 1c). They involve degree modification along a bounded, closed scale, as the quality 'true' is a bounded one: something either is or is not true. The LME and EModE data contain a number of examples that seem to be interpreted best as bridging contexts, such as (13). Because of the scientific context and the definiteness of the NP pe verri sope, (13) supports both a descriptive reading, 'true, corresponding to fact' and an intensifying reading. ${ }^{6}$ Such contexts suggest how functional re-interpretation came about. On its descriptive modifier reading very and the nouns truth or sooth share their main semantic features. This semantic redundancy promoted the functional reanalysis of very as a scalar modifier which intensifies, rather than adds semantic content to, the nominal description.

(13) But truly I haue goon to alle pe grettiste charnellis ('charnel houses')..for to prouen ('prove') by experience pe verri sope. (MED c1475(1392), *MS Wel.564)

The very truth has remained in use as a fixed phrase throughout LModE and into PDE, while the phrase the very sooth disappeared together with the noun itself in EModE.

The second collocational environment that triggered degree modifying uses of very in LME is concerned with typifying persons. The relevant source meanings of very described properties of people, such as 'faithful, loyal' of nouns like wife, friend, servant, and 'truthful' of nouns such as prophets. Examples bridging between

\footnotetext{
${ }^{6}$ We thank our second anonymous referee for pointing this out to us.
} 
descriptive and noun-intensifying meanings, such as (14), again suggest how the change took place. In (14), very can be read as a descriptive modifier ascribing the quality of loyalty to knight. On the other hand, it can be understood as an emphasizer, whose meaning is glossed by the MED as 'possessing the specified character in its full and genuine form, worthy of the name: knightly, wifely, faithful, etc. [the precise meaning is dependent on the context]' (verrei 3b). In (14), very does not grade the nominal description, but rather comments on the match between referent and description. In this respect, it resembles the meaning of very found in fixed collocations such as very man and very god (example (4) above) with this difference that an emphatic meaning element is added. ${ }^{7}$ Presumably, the qualities of 'faithfulness', 'truthfulness', etc. were felt to be key properties of the human types in question and hence the combination of $v e r y+$ noun came to convey that individuals exhibiting the key property are exemplary or full-fledged instances of the type. Such examples are best analyzed, we propose, as subjective descriptive uses, expressing an evaluation that is a matter of the speaker's opinion (Quirk et al. 1985: 1341).

(14) Wele ('well') hap Gij ('you') don pat day, As gode knizt ('knight') \& verray. (OED a1400, Warwick)

In a second stage, very lost further denotational content and acquired scalar meaning with person-describing collocates: it intensified the gradable qualities inherent in a noun such as fool either along an open scale ('very foolish') or along a closed scale ('a fool in

\footnotetext{
${ }^{7}$ Méndez-Naya (2006) identifies a similar shift in the history of the adjective right from emphasizing the 'exactness' of the denotation of the accompanying item to changing its 'degree'.
} 
every respect') (p.c. William Croft). In this use, it modifies the degree of specific qualitative features implied by a 'degree noun' (Bolinger 1972: 58-60). Very followed the typical subjectification path of transforming some of its descriptive modifier senses into scalar meanings. The subjectification process was accompanied by collocational expansion, giving rise to examples such as (15) and (16) in which the nouns being intensified do not imply any qualities describable by very such as loyalty or truthfulness.

(15) He..is a very fole. (OED 1484, Caxton)

(16) 'Now I am a verry wreche,..!' (PPCME2 1420-1500, Malory)

Noun-intensifiers of human types are attested from the end of the 15th century, peak in our EModE data (according to the OED from $c 1550$ to $c 1700$ ) but remain frequent in the LModE data, ${ }^{8}$ before falling out of use in the PDE data.

A third collocational environment in which degree modifying uses of very emerged in LME contained nouns designating emotional states and dispositions. They appear to have been triggered with descriptions of emotions that are intense (17) or even paradoxical (18).

(17) Than Percyvale wepte for verry pite ('pity') when he knew hit was hys awnte ('aunt'). (PPCME2 1420-1500, Malory)

\footnotetext{
${ }^{8}$ According to Brugmann (1984: 28) the referent-intensifying use in indefinite NPs occurred 'rarely after the 16th century', but we found it to be still rather common in the - admittedly literary - data of the CLMET.
} 
(18) She gynneth ('begins') to wepe For verray joye (OED a1440, Partonope)

Some of these can be interpreted either as noun-intensifier or as exclusive focus marker, meaning 'nothing but' (see Section 4.4.2), e.g. (19).

(19) Al is verai tricherie,..The more he swerth ('swears'), the more he lieth. (MED a1393, Gower)

Noun-intensifying uses of very with emotions, attitudes, and inclinations gradually dropped out of use before disappearing in PDE.

In the final pattern, which is attested only from EModE on, very collocates with nouns expressing a beginning, end or middle point in space or time, e.g. the very end (20), the very top, the very bottom.

(20) ..almost at the very ende of this towne cummith a litle broke.. (PPCEME 15001570, Leland)

The origin of this intensification pattern lies, in our view, in the 'precise' sense, which was commonly used with nouns denoting a point in space or time, as in (6) above, the very time. It is in combinations with a specific subset of these locations, viz. the beginning, end or middle of an extent in space or time or in a metaphorical domain, that the intensifying use developed. These locations are fixed with respect to the extent and when very in its descriptive 'precise' sense combines with them, this creates semantic redundancy, as their location is inherently known. This, we suggest, caused the 
inference that the very end is the 'most extreme' end of a larger 'end section' on the spatial or temporal extent, as clearly illustrated in (21). In other words, the bounded descriptive meaning was reinterpreted as a closed scale intensifier, with very marking the extreme of the scale.

(21) the point of your hook may come out toward the head-end ... then put the point to your hook into the very head of the worm. (PPCEME 1640-1710, Walton)

This noun-intensifier pattern is still attested in LModE and PDE, but restricted to some fixed phrases.

Structurally, the shift to the noun-intensifier function involves movement to a more leftward position than descriptive modifiers. As illustrated by (21), very can also have scope over the combination of head noun and descriptive postmodifier. In the structural assembly of the NP, the noun-intensifier logically follows the integration of head and any classifying or descriptive modifiers it may have. Semantically, the speaker-related meaning of subjective scalar assessment changes the descriptive material in its scope (McGregor 1997: 67).

The noun-intensifier uses are found in roughly four subsets from the sets of collocates circumscribed by the descriptive senses. They expanded some of these sets to include nouns whose meanings are negatively coloured. They attained their highest relative frequencies in LME (7\%) and EModE (6.5\%), as shown in Table 1. None of the patterns expanded to a very wide range of noun-collocates. No general noun-intensifier use emerged and the constructional schema gradually lost its productivity, with a few 
expressions such as the very truth, the very end and the very beginning surviving as lexicalizations.

\subsection{Very as focus marker}

More or less at the same time as the noun-intensifier uses, very developed focus marker uses (first OED attestation $c$ 1386). In this NP function, very serves a function similar to focusing adverbs (König 1991, Nevalainen 1991), focusing on a value relative to alternative values (cf. Eckardt 2012: 299-304), and expressing the same relations as even, only and just. Very in (22) conveys inclusive focus ('even'), i.e. an extreme on a scale implying all other points on it. That the enemy pursued them 'as far as' their tents implies all the other points on the trajectory of the pursuit. In (23) and (24), very expresses exclusive focus ('only'), excluding all other alternatives. (23) is non-scalar, or 'categorial' (Nevalainen 1991: 31): nature itself is contrasted with art, while (24) illustrates the scalar meaning, which focuses on 'the mere' mention of the word steak that makes her salivate in implied contrast with other things such as the smell or taste of steak that can be ranged on a scale as more likely to make her salivate. In (25) very has a particularizing meaning ('just'), delineating the focus value with greater precision: it was precisely the feature of modesty that first struck the writer.

(22) ... they... fled before the enemy, who pursued 'em to the very tents, killing 'em. (PPCEME 1640-1710, Behn)

(23) There needeth no art, bicause very nature hir selfe createth and shapeth men apt to expresse pleasantly. (OED 1561, Hoby)

(24) Diana found herself salivating at the very mention of the word steak. (WB) 
(25)

..modesty seldom resides in a breast that is not enriched with nobler virtues. It was the very feature in his character that first struck me. (CLMET 1780-1850, Goldsmith)

\subsubsection{Inclusive focus marker}

The inclusive focus marker use appears to have emerged first, with the early $c 1386$ OED attestation in (26), contemporaneous with the first noun-intensifier uses.

(26) Ran cow and calf, and eek ('also') the verray hogges Sore ('greatly') fered ('fearful') were for berkyng of dogges. (OED c1386, Chaucer)

(27) They goo like a prisoner that were ouergrowe ('overgrown'). They be couered ('covered') with heere ('hair') even to the verri Iowe ('jaw'). (PPCME2 14201500 , Idley)

We propose that in inclusive focus marker uses, very invokes a scale of surprise or unexpectedness (Eckardt 2012: 302), i.e. a mirative (DeLancey 1997) scale, locating the referent entity at the top of the scale (The OED II. 8a uses the gloss 'exceptional prominence' for these uses). For instance, very in (26) focuses on hogs as the animals that most surprisingly fear dogs in comparison with cows and calves, which one would expect to fear dogs. Its inclusive meaning is contextually supported by the adverb eek 'also'.

The immediate source of this focusing use is probably the descriptive sense 'endpoint of an extent', which via metaphorization and abstraction provided the semantic component 'extreme of a scale', which is crucial to this focus marker use. This 
hypothesis is supported by the many examples where a spatial scale is coupled to the mirative scale, as in (27), where hair grows down from the head, over the ears and cheeks, and even as far as the jaw. Brugmann (1984: 22) also links inclusive focus marker uses to the descriptive 'extreme' sense, noting that ' $[v]$ ery is used in these cases to impose ... the structure of an extent' even though '[t]he noun phrase does not refer to an inherent subpart of the extent'. In other words, these focus marker uses imply a scale, which is conceptually derived from the sense 'extreme point of an extent'.

This scenario receives further support from the fact that bridging examples occur such as (28) in which very can be interpreted as either an inclusive focus marker ('even at the beginning of our acquaintance') or a noun-intensifier ('at the utter beginning of our acquaintance'). The inference linking the two readings is that something being located at an extreme may be a cause for surprise or mirativity.

(28) I was annoyed at the continual injustice she had done me from the very dawn of our acquaintance (CLMET 1780-1850, A. Brontë)

The inclusive focus marker use became rather popular towards the end of the EModE period and in LModE, but dropped off in use in PDE.

\subsubsection{Non-scalar exclusive focus marker}

The other early focus marker use (earliest OED attestation $a 1387$ ) expresses non-scalar exclusive focus. It delineates the instance referred to as the focus value, against all other possible alternatives, which may be contextually supported by other elements, e.g. itself 
(30). It is often found in contexts that explicitly mention a contrastive value, e.g. the standardys - the deede (29), the malice of my enemyes - the danger of death (30).

(29) The standardys ben displayed agains the enmyes ('enemies'), but the verray deede is agains me. (PPCME2 1420-1500, *Chartier Quad.(1))

(30) [...] if avoyding the malice of my enemyes, or the very danger of death itselfe, (PPCEME 1570-1640, Hayward)

It seems plausible that one source lies in the 'true as opposed to false' meaning, which, as noted by the OED (very, A. adj. I 2a) entails 'limitation to particular instances' (OED I 2a), opposing them to ones that are not genuine instances. Example (31) illustrates this inference of the descriptive sense 'true': recognizing 'genuine blissfulness' entails limiting it to 'what alone is blissfulness'. The focus marker use no longer contrasts the real, or only, instance of a type with false contenders, but contrasts the value that applies in a context with the alternative(s) that do not

(31) as thou hast knowen which is thilke ('this') verray blisfulnesse, and eek whiche thilke thynges ben that lyen falsly blissfulness -- (PPCME2 1420-1500, Chaucer)

As suggested by the common occurrence of bridging contexts supporting both an exclusive focus and a noun-intensifier reading, as in (32), the latter is another plausible source. The nouns in such bridging examples designate emotions (for verray fere, OED 1405) and other abstract notions (for very age, OED 1535) as the cause of the state of 
affairs in the matrix. The inference linking the two readings is probably that a very strong emotion or force is bound to be the only cause of the state of affairs in the matrix.

(32) $[\mathrm{He}]$ throu ('through') verray fors ('force') was the first lorde of that realme. (OED $c 1485$ (c1456), Hay)

The exclusive focusing meaning is the most frequent of all focus marker uses in the LME and the earliest EModE data, and it remains relatively frequent in LModE. It is still used in PDE, but its frequency has dropped drastically.

\subsubsection{Particularizing focus marker use}

In the final stage of ME, the particularizing focus marker use of very appeared (earliest OED attestation $c 1465)$, which singles out the referent from a set of implied contrastive options, as in (33) and (34). It is often contextually supported, e.g. by being construed as the focal, identifying element in identifying clauses such as (33) and (34).

(33) 3Pe welfare of Edward Rex moste riall ('royal'), That is pe verie purpos that we labure ('labour') fore ('for'). (OED c1465, Pol., Rel., \& L. Poems)

(34) This is the very land of refuge that English pirates resort most unto. (OED 1521, Cal. Carew MSS)

Most probably, the particularizing meaning developed from the categorial exclusive focus meaning, by backgrounding the contrastive options into an implied set and 
foregrounding the singling out of the focus value. The particularizing focus use of very remained rather marginal in LModE and became more so in PDE.

\subsubsection{Scalar exclusive focus marker}

The non-scalar exclusive use quickly led to scalar exclusive focus marker uses in the last stage of ME (1450-1500), whence it persisted into PDE. This use locates the entities being contrasted on an evaluative scale, more specifically at the bottom of the evaluative scale, making very paraphrasable by 'mere', e.g. 'their mere stipends and wages' (35). This new focusing meaning is often supported by contextual clues such as no other ... but in (35).

(35) Having no other promocions but theyre verye stipende or wages. (OED 1548, Page)

(36) So give me leaue, in a very word or two, to congratulate with you. (OED 1557, Cromwell)

\subsubsection{Focus markers: conclusion}

Structurally, very as a focusing adjective occurs in the position most leftward of the descriptive material in the NP. Semantically, it focuses on the whole nominal referent, e.g. (34) above, or on an aspect such as its quantity, as in (36) above, in relation to the state of affairs expressed by the clause. The focus marking uses of very attained their highest relative frequency in LModE, $15.8 \%$, but have clearly gone out of fashion in PDE, with a proportion of only $3 \%$ of the data (See Table 1). The main surviving 
vestiges are the exclusive focus marker uses in phrases such as the very idea and the very thought.

\subsection{Very as adjective/adverb-intensifier}

In this section we reconstruct the developments by which the adverb very acquired the function of intensifying adjectives (and adverbs). In the previous sections we saw that the adjective very developed the functions of noun-intensifier and focus marker towards the end of the $14^{\text {th }}$ century. It was also in that period that adverbial very began to be used as a modal qualifier of predicative adjectives (first OED attestation a1387), with the meaning 'truly', as in (37)-(41). The adverb very resulted from a category shift that had first manifested itself in the combination of verbs and lexical adjuncts such as $a l$ verray quat, 1375, 'all that is truthfully spoken' (OED very B. adv. 1). In (37)-(39), by contrast, very is used as a modal subjunct (Quirk et al. 1985: 448), by which the writer commits to the truth of the part of the proposition expressed by the adjective or participle. Such modal adverbs are found with adjectives that have positive (e.g. repentaunt), neutral (frenshe) or negative (e.g. peynful) affective colouring (Sinclair 1991: 70ff.), and either bounded $(37,39)$ or scalar $(38)$ meanings. ${ }^{9}$ In all these respects, the adverbial modal qualifier imposed few collocational constraints, even though it was not bleached of its modal meaning.

(37) But for he was verray repentaunt he was exciled for pe fey ('truthfulness'). (OED $a 1387$, Trevisa)

\footnotetext{
${ }^{9}$ Table 2 gives the frequencies of the lexical adjunct and modal subjunct uses of very in the OED citations.
} 
(38) And in al this tyme sche ('she') had no lust to comown ('comune') wyth hir husbond, but it was very peynful \& horrybyl vnto hir . (PCCME 1420-1500, Kempe)

(39) Two thousand knyghtes.., \& all yonge men of pryme berde ('new beards'), whiche were very frenshe. (OED 1490, Caxton)

As observed by Lorenz (2002: 151-2), stating that something 'truly' has a quality invites the inference that the quality holds true to a large extent. Modal adverb uses of very as in (38)-(39) can therefore be viewed as a first immediate source of adjectiveintensifiers, as shown by the occurrence of bridging contexts such as (38) in which the modal qualifier meaning is '[n]ot always clearly distinguishable from' (OED very, B. adv. 1.b) the intensification of adjectives. The modal adverb uses can be viewed as the first occupants of the adjective-intensifier slot. Isolating contexts in which very can only be interpreted as an adjective-intensifier (as in (42)-(43) below), are attested only from the last period of ME on (roughly the second half of the $15^{\text {th }}$ century).

The second pathway of a categorial and functional shift leading to adjectiveintensifiers has its source in two coordinated adjectives (Adamson 2000). The first adjective, through increasing subjectification of its meaning, is reinterpreted as an intensifier of, rather than a descriptive modifier on a par with, the second adjective. A prerequisite for this shift is the possibility of perceiving the first adjective as either structurally coordinated with or subordinated to the second. Our ME data, both from the PPCME2 and the OED, contain several examples in which very is asyndetically coordinated with a near-synonym expressing the descriptive subsense of very at stake more clearly, e.g. 'truthful' in, a very trewe evidence (OED ?a1450), a very true Copie 
of the Recorde (OED, 1472), and 'faithful, loyal' in the very trewe Lucresse (OED $1385)$, the very trewe lover of crist (OED, c1450), very ryght secoure (OED, 1483), very true obedyence (OED 1497), and my veray ffeiztheffull Cossen (40).

(40) My veray ffeiztheffull ('faithful') Cossen ('cousin'), I trust to you pat.. (PPCME2 1420-1500, Stonor)

In these combinations, very is semantically redundant with the adjective that follows it. As a result, the meaning of very proper loses denotational content, allowing it to combine with more adjectives. This eventually led to the functional reparsing of very as intensifying submodifier of the other adjective. An example of a bridging context is (41), in which very can be read as 'truthful' or as an intensifier of wise.

(41) And very wyse men comynly ('commonly') ordre ('order') wel al theyr dedes (PPCME2 1420-1500, Fitzjames)

The mechanism of change, semantic redundancy leading to reinterpretation of very as an intensifier, is analogous to that found with adjective-noun combinations such as very sooth (11) and very end (20) (see Section 4.3).

We propose that these two pathways interlocked and mutually reinforced each other, leading to $6.5 \%$ examples in the last stage of ME, 1420-1500, in the PPCME2-data (Table 1), in which very can only be interpreted as a bleached, adjective-intensifier, e.g. (42)-(43). In the same period, very started submodifying adverbs (first OED attestation 
1448), which describe qualities in relation to an event or situation, e.g. veré hartely in (44).

(42) Here all vayne marchaundyses of the worlde bene bought, to the whiche is very prone and redy oure youthe of Englonde, (PPCME2 1420-1500, In Die Innocencium)

(43) The hawke will be very eegre and gleetous ('affected with phlegm') of the sekenes ('sickness'). (OED 1486, Bk St Albans)

(44) Veré hartely your, Molyns. (OED 1448, Paston Letters)

There was thus expansion of the grammatical classes that very could combine with. Importantly, the sets of lexical collocates and their affective colouring also extended. In the examples that allow an interpretation of very as an adjective coordinated with a second adjective, e.g. my veray ffeiztheffull Cossen (43), very shares semantic features with that second adjective, which always denotes a positive quality. Bleached adverbial very by contrast could intensify adjectives which it did not share semantic features with and which can have a negative aura, as in very prone and redy (42) and very eegre and gleetous (43).

The EModE and LModE data show dramatic, exponential growth of adjective/adverb-intensifying very, which accounts for $79.15 \%$ and $66 \%$ respectively of these datasets. The ModE data also evidence further collocational expansion, and the lifting of restrictions on the modified adjective or adverb, as illustrated by (45)-(49). 
(45) Those fowlys ('birds') the ar full ('very') far fro me And werie yvill ('hard') for me to fynde. (OED a1500-34, Cov. Corp. Christi Pl.) ..eate very moderately..(PPCEME 1570-1640, Paston Letters)

(47) put it into a very cleane boule of wood, (PPCEME 1570-1640, Markham)

Very construed more or less from the start open-scale degree modification (Paradis 2000, 2001; Kennedy \& McNally 2005) both for typically unbounded adjectives such as yvill ('hard') and, as a marked construal, for typically bounded adjectives such as clean. It indicates a degree of those qualities which is 'up' from an implicit reference point (Pander Maat 2006) on an open scale. From the start of EModE on, very is also found with adjectives in the superlative form, which function either as descriptive modifier, as in (48), or as head of the NP, as in (49). The superlative of a scalar quality such as rich locates the quality on the extreme end of the scale. As a result, very emphasizes the extreme end of the closed scale conveyed by the superlatives (Paradis 2000: 52). Even though it is the bleached intensifier that combines with superlative adjectives, the collocating superlatives seem to form a restricted set including the very poorest/richest/best/worst.

(48) Three of the very richest subjects in England. (OED 1849, Macaulay)

(49) How then should the very Best of us..expect..to be free from them? (OED a1732, Atterbury)

In the grammatical structure of the NP, the intensifying adverb very has narrow scope, viz. only over attributive adjectives functioning as descriptive modifiers, whereas 
the noun-intensifier and focus marker uses of the adjective very hold the nominal head + any descriptive modifiers in their scope. In this sense, the modification relation between adverbial very and the attributive adjective is situated more to the left in NP-structure than that of the noun-intensifier discussed in the previous section.

The collocational expansion that took hold of adjective/adverb-intensifying very, once it was properly launched at the beginning of EModE, acquired its own momentum, leading to further loss of lexical content and generalization of the meaning of very. Very is generally recognized to be the most frequently used and most 'general purpose' intensifier of adjectives (Lorenz 2002: 145-6). In our PDE data (Table 1), the proportion of adjective/adverb-intensifiers has risen to $86.5 \%$, making this by far the predominant function of very.

\subsection{Very as classifier}

In LME and EMoE, very developed a marginal and short-lived classifier use, mainly very heyre ('heir') illustrated in (50), in which very restricts the denotative scope of the noun it accompanies, and the resulting unit participates in taxonomies (Halliday 1994: 184-5) denoting contrastive and synonymous subtypes such as false heir and heir apparent. This classifier use of very had become obsolete by LMoE (see OED, very A. adj. I. $\uparrow 7$ ). This minor, aborted path of change saw very moving to a position to the right of the descriptive modifier and forming a fixed collocation with the head noun. It is a clear case of lexicalization yielding an objective denotation, i.e. the type of change associated by Adamson (2000) with 'rightward' moving functional shift. 
(50) I am very heyre, by the discease of my fader, to a place called Keswyk. (OED a1466, in Paston Lett. \& Papers)

\subsection{Very as intensifier of postdeterminers}

Right at the end of ME, adverbial intensifier very extended from modifying attributive adjectives to modifying postdetermining adjectives such as same in (51) and (52) and self in (53) (first OED attestation ?a1500). Whereas the former are referent-oriented, describing the thing in question, the latter are reference-oriented (Bolinger 1967), aiding the identification of the referent. Looked at purely in terms of grammatical classes, we have adverbial very modifying an adjective in both patterns, but in structural terms, the intensifier of postdeterminers has moved leftward in NP structure, submodifying a different, more leftward element of structure. Semantically, this use of adverbial very is not scalar but emphasizing. In (51)-(52) very adds further emphasis to the postdeterminers same and self, which themselves already emphasize the singling out of the correct referent(s) (Breban 2010b). The entire determiner unit can be paraphrased as 'exactly the same'.

(51) This is the blynde man which yster daie ('yesterday') Asked our almes..: It is the vereye same. (OED ?a1500, Chester $P l$.)

(52) he is like the Buck or the Ox , that will not be fat in many months, though he go in the very same pastures that horses do, which will be fat in one month, (PPCEME 1640-1710, Walton) 
(53) ther the hye ('high') Auter ys of the same Chapell, ys the very self place wher our Savyor Christ aftyr hys Resurerection ffyrst apperyd vnto hys blyssyd mother. (PPCEME 1500-1570, Torkington)

The piling up of emphatic elements in the very same, the very self, the self same, etc. can be explained by the fact that these elements, through frequent use, quickly lose their expressive force, which is then compensated for by adding a new emphatic element. The additional intensification with very is often found in contexts in which identification is not straightforward pragmatically. In (52), for instance, very conveys that 'exactly the same' pastures that fatten up horses do not fatten up bulls and oxen. Very may also be added in contexts of complex referent identification such as (53), which stresses the identity of reference between the antecedent and the phoric NP with the very self and also points forward to the identifying information in the relative clause.

As an emphasizer of postdeterminers, very extended later on to numerical (e.g. first, 54) and non-specific (e.g. next, 55) ordinals functioning as postdetermining adjectives (first OED attestation 1654), emphasizing the specific position on the ordinal scale designated by the postdeterminer.

(54) I could hang my self for being such a sot; especially the very first night after I was Married, and not to go to bed to my bride, (PPCEME 1640-1710, Pepys, Penny merriments)

(55) This fel out to be the verie next day after Qeen Elizabeths deceased. (OED 1654, Gataker) 
This shift may have been enabled by the conceptual analogy between indicating points on a qualitative scale, e.g. very richest in (50) above, and points on the ordinal scale which underlies the meaning of complex determiners such as the very first (54) and the very next (55). The conceptual analogy between the qualitative scale of degree modification and the quantitative scale of ordinality was pointed out in Brugmann (1984: 22).

\subsection{Very as intensifier of quantifiers}

About a quarter of a century after its emergence as adjective intensifier in the OED citations, the bleached adverb very came to modify indefinite quantifiers (first OED attestation a1578) such as many in (56), few in (57), little and much, etc. Very changes the quantity indicated, augmenting it in examples such as very many/much and diminishing it in cases like very few/little. This shift was enabled, we venture, by the conceptual analogy between ranges of qualities, measured on qualitative scales, e.g. clean in (46) above, and ranges of quantities, measured on the non-specific quantitative scales derived from the cardinality scale (Langacker 1991: 82-3). Whereas qualityintensification modifies the degree of the quality, boosting or diminishing it (Quirk et al. 1985: 583-601), quantity-modification changes the actual quantity, augmenting or reducing it.

(56) The said pest come in the towne of kirkcaldie that thair deit ('died') verrie mony. (OED a1578, Lindsay)

(57) Batha, whereof now there remaine but very few ruines. (OED 1600, Pory) 
Because adverbial very precedes the element it modifies, very occupies its most leftward function in NP-structure as a submodifier of quantifiers.

\subsection{Very as postdeterminer}

In Sections 4.7 and 4.8, we have seen how adverbial very moved further leftward in NPstructure, from the intensification of adjectives to the 'intensification' of postdeterminers, as in the very same, and of quantifiers, as in very many. In this section, we will see how the adjectival intensifier very likewise moved further leftward in NPstructure from the intensification of nouns to the 'intensification' of determiners (Bolinger 1967: 19), as in that very hour (58), this very day (59), paraphrasable with 'precisely', i.e. 'precisely that hour', 'precisely this day'. These uses fall under the postdeterminer function, in which elements following the determiner modify it to express identification more precisely. Very came to function as a postdeterminer first to demonstratives (first OED attestation 1577) and then to the definite article (see (62)(64) below).

(58) Luke x. 20 In that very houre he reioyced in spirit. (OED 1582, Bible (Rheims))

(59) The present occasion of this dispatche is shortly this. This very day advertysement is come to the Queene of the ffleet of Spaine .. (PPCEME 15701640, Cecil)

Breban (2010b) has pointed out that, as a postdeterminer 'aiding' identification (Halliday 1994: 185), very could also help express anaphoric or cataphoric pointing, as in (60) and (61). In (60) that very thing points backward to the whole preceding 
sentence, which forms its antecedent, while in (61) that very thing gives instructions to retrieve the actual referent from the following discourse as a 'postcedent'. Bolinger (1967) did not discuss this second use of very as a postdeterminer, but the OED entry for the postdeterminer use (very A1 10) could be argued to distinguish the two senses in the gloss 'Used (after the, this, that, etc.) to denote or emphasize [italics ours] complete or exact identity': whereas very in (58), (59) emphasizes the deictic force of that and this, it designates the phoric co-referentiality relation in (60) and (61).

(60) hee endeavored to gaine an injunction and to hinder the examination of what I have been damnified; and in that very thing before the Lords Commissioners att Westminster Hall, I foyled ('outdid') him once more; [...] (PPCEME 16401710, Oxinden)

(61) he commends the Bereans for that very thing for which I dare say the Church of Rome would have check'd them most severely, namely, for searching the Scriptures to see whether those things which the Apostles delivered were so or not (PPCEME 1640-1710, Tillotson)

The postdeterminer use of very extended to the definite article, with examples such as (62)-(64). Very in (62) can be interpreted either as emphasizing the ('precisely the place') or as together with the designating an anaphoric relation ('the same place'), expressing token identity (Brugmann 1984: 23) between the place where the church used to be and where the market is now. In (63) the very seems to combine the emphasizing and anaphoric meaning, 'precisely the same smell'. In (64) the very seems to have phoric meaning only, pointing both to its antecedent and the identifying 
information in the following restrictive relative clause. The co-referentiality between the earlier mentioned referent and that of the current NP is made explicit by formerly mentioned.

(62) There hath bene ... a paroch church by the name of Alhalowes. The very place wher the market stede and the hart of the towne is. (PPCEME 1500-1570, Leland)

(64) Some offence there is in the smell thereof; and yet it is wrytten of it that the very smell therof is comfortable and yeldeth streyngeth to the brayne. (PPCEME 1570-1640, Ellis)

(64) I had recourse to the very vigorous piece of polish'd Amber formerly mention'd (PPCEME 1570-1640, Boyle)

Breban (2010b) pointed out that the adjective same in postdeterminer function also shifted from emphasizing the meaning of the determiner to expressing a phoric relation. A typical bridging context is formed by an example such as (65), in which the same expresses that the time of the child's healing was 'precisely the hour when Christ spoke': token identity has to be established between the (implied) antecedent and the NP the same hour, whose precise temporal location is spelt out by the restrictive relative clause. The instructions for phoric retrieval would be less clear if same was left out. Such examples led to purely phoric uses of same as in (66). It may well be that analogization with same was the mechanism of change by which very first emphasized the determiners that/this/the and then, together with them, expressed phoric instructions. It therefore seems quite possible that very followed the model of same, which was 
commonly used with these meanings in the same structural configurations (Hopper \& Traugott 2003: 63-64, Traugott \& Trousdale 2010: 38) (see also De Smet 2012 on semantic and distributional analogization).

(65) Tei seyden pat zusturday ('yesterday') pe seuenepe ('seventh') howr ('hour') be feuerys ('fevers') forsoken pe child. And pe fadyr ('father') knew by his mynde pat hit was pe same owr ('hour') pat Crist seyde 'pi sone lyuep ('your sone lives')'. (LEON 1351-1420)

(66) 'By Marie,' quod ('said') a mansed preste of pe marche of yrlonde, 'I counte namore ('no more') conscience'. And so seide sexty ('sixty') of pe same [vr. Sane] contreye ('region'). (MED c1400(c1378), PP1B (Ld))

The phoric meaning of very proved a marginal phenomenon in comparison to its intensification of determiners. The phoric uses increased to one quarter of the postdeterminer uses in the LModE data, but have disappeared in PDE.

\section{CONCLUDING DISCUSSION}

This study set out to reconstruct the diachrony of the many different uses of very in functional-structural terms. In Section 2, we further developed our earlier syntheses of the functions of (sub)modifiers in the English NP. We explicated the precise units involved in the modification relations, and their semantic computation, which differs for descriptive and interpersonal modifiers (McGregor 1997). In Section 4, we reconstructed the emergence of all the basic functions very has fulfilled historically as 
well as of the finer subsenses that can be distinguished on the basis of collocational and pragmatic distinctions.

This reconstruction allows us in the first place to confront the development of very with Adamson's (2000) hypotheses about the structural and semantic directionalities of change in the English NP. Very appears as a paradigm case of Adamson's hypothesis that the acquisition by adjectives of new functions with more subjective and grammatical value involves 'leftward movement' in the prenominal NP-string.

We found that very was borrowed into English c1250 as part of fixed collocations, e.g. warrai man and god warrai. It detached itself from these entrenched, fixed expressions around 1300, acquiring the function of predicate (e.g. 3if pe relikes verray were, $\mathrm{OED}, 1329)$ and descriptive modifier (e.g. pe verrey valowe, OED, 1338). Around 1385, the adjective very acquired two new functions, with more subjective and grammatical meanings - both realized by interpersonal pre-modifiers that semantically 'overlay' the lexical material to their right. These were - illustrated with their first OED attestations - the noun-intensifier (e.g. a verray propre fole, OED, 1384) and the focus marker (e.g. eek the verray hogges Sore fered were for berkyng of dogges, OED, 1386). With a noun-intensifier the speaker assesses the gradable features of the nominal description relative to scales, which is a subjective type of meaning. With a focus marker, the speaker negotiates a specific location of the focus value vis-à-vis alternative values taking into account the hearer's presuppositions and expectations, which is an intersubjective kind of meaning.

Adverbial very, developed from adjunct (al verray quat, OED, 1375) and subjunct uses (e.g. verray repentaunt, OED, 1387), into the bleached adverbial intensifier, which came to modify descriptive adjectives as well as adverbs in the final stage of Middle 
English. Intensifiers convey subjective meaning as they express the speaker's scalar assessment of the qualities in question. The bleached intensifier then moved into the determiner zone, first, around 1500, as submodifier of postdeterminers, e.g. the vereye same (OED, ?a1500), and then, around 1578, as submodifier of quantifiers, e.g. verrie mony (OED, a1578). It is with this last functional shift that very reached its most leftward position in NP-structure. The meaning of determiners (in the broad sense) is textually intersubjective, because they are used by speakers to introduce and track referents in the discourse in a way that takes into account the hearer's knowledge. The submodifier uses of very partaking in these functions contribute to the textually intersubjective content of the NP.

In Early Modern English (c1577), adjectival very also moved further leftward into the determiner zone. More specifically, it moved into postdeterminer position, where it emphasized or denoted referential identity, e.g. that very thing (1577), that very houre (1582). That is, it acquired textually intersubjective meaning.

In sum, the chronology in which very acquired its new functions coincides almost perfectly with its progressive leftward movement. Regarding the directionality of subjectification, adjectival and adverbial very first acquired their purely speaker-related degree modifier functions, before moving on to the intersubjective focus marker function and various textually intersubjective functions in the determiner zone. These changes involved further host class expansion to the grammatical classes of determiners and quantifiers. The fact that very conquered the functional zone of determination so quickly and extensively has, in our view, to be ascribed to the fast progressive loss of lexical content it had undergone through its prior development of focus marker and intensifier uses. With its various functions in the determiner zone, it reached the final 
stage of loss of denotional meaning. Méndez-Naya (2003: 389) argues that adverbial intensifier very is completely grammaticalized and that it is this property that shields it from being renewed, despite the fact that its expressivity as an intensifier has worn out.

The minor path of change towards the classifier function exemplified by very heir involves rightward movement and lexicalization, as predicted by Adamson (2000).

The verification of Adamson's hypotheses made us focus on the uses that first realized each function. However, just as importantly, our analytical model allowed us to reconstruct the further uses that developed within each function, and to pinpoint the uses that disappeared. The latter are an important part of the history of very as well. Of the noun-intensifier, focus marking, and postdeterminer functions only some subtypes survive in Present-day English. Thus, we arrive at what is - to our knowledge - the most comprehensive description of the grammatical functions fulfilled by very in its history, and the more specific collocational and pragmatic distinctions within these functions.

Our model also helped us lay bare the various mechanisms and factors involved in these chains of developments. Importantly, we found that different factors are involved in different types of change.

In the chain of changes by which descriptive modifiers were reanalyzed as intensifying modifiers, crucial factors were both pragmatic mechanisms (Traugott \& König 1991) and various collocational processes such as semantic bleaching due to semantic redundancy, lifting of semantic prosody, etc. In fact, the pragmatic mechanisms were often embedded in collocational processes. For instance, entailment played a role in the semantic development by which very, from expressing the match between name and referent, came to designate a distinct property as a descriptive 
modifier or predicate. This semantic differentiation of very came about in its spread to different sets of nominal collocates such as truthfulness applied to spoken or written messages, preciseness to times, places and (financial) value, faithfulness to partners in a relationship of marriage, friendship or service. Specific subsets of these collocational sets provided the input for the subsequent reanalysis of descriptive modifiers into nounintensifiers. In this reanalysis, pragmatic mechanisms such as invited inference played a role, e.g. from the 'precise' sense to the most extreme end of a larger section with the very end. Again, these mechanisms were operative in collocationally defined sets, and collocation-bound processes such as bleaching due to semantic redundancy and lifting of semantic prosody were important factors.

By contrast, the development of the focus marker seems to have been driven mainly by pragmatic factors. Very developed all main types of focus marking via pragmatic inferences. On the one hand, the 'extreme' sense found in collocation with extent nouns generalized into uses inviting readers to infer the mirative scale typical of inclusive ('even') focus marking. On the other hand, the descriptive subsense 'genuine/true as opposed to false' led first to non-scalar exclusive focus, then to particularizing focus, and finally to scalar exclusive focus. It is also striking that nounintensifier and scalar focus marker uses of very emerged contemporaneously, linked by inferences such as the following: a qualitatively boosted force is likely to be the only causative force of a situation (exclusive scalar), a situation being taken to a spatial extreme, or being located at a temporal extreme, has surprise value (inclusive scalar). The origins of the focusing uses of very may be traceable to collocationally specific bridging contexts but the further development of the focusing uses detached very increasingly from collocational restrictions. Any focus value can be contrasted with 
(implied) alternatives or can be situated relative to alternatives on inferred scales (Eckardt 2012). The detachment of focusing very from specific collocational sets was thus pragmatically driven.

Finally, the development of the intensifiers of postdeterminers and quantifiers, and of postdeterminers seems to rely mainly on analogy with other modification patterns. The analogy may be with similar modification patterns involving very elsewhere in the NP, such as the analogy between quality (very good things) and quantity modification (very many things). In addition, semantic analogization may have been at work between very and other elements such as same/self in the same structural relations, for instance between complex determiners such as the self same and the very same (Section 4.7), and between postdeterminers the same and the very (Section 4.9).

A second key conclusion of our study is thus that different types of functions develop via different mechanisms of change. Much more research needs to be done on this, perhaps particularly on the interaction between pragmatic mechanisms of change and collocational factors. However, an analytical model distinguishing basic grammatical functions from more context-bound subsenses seems a promising way for detailed reconstruction and explanation of historical language change. 
Authors' addresses

Tine Breban

Department of Linguistics and English Language

The University of Manchester

Oxford Road

Manchester

M13 9PL

United Kingdom

E-mail: tine.breban@manchester.ac.uk

Kristin Davidse

Department of Linguistics

University of Leuven

Blijde Inkomststraat 21

3000 Leuven

Belgium

E-mail:kristin.davidse@kuleuven.be 
COPORA AND DATABASES

$\begin{array}{llllll}\text { Corpus of Late Modern English Texts, version } 3.0 & \text { (CLMET): }\end{array}$ //perswww.kuleuven.be/ u0044428/

Leuven English Old to New Corpus (LEON): //perswww.kuleuven.be/ u0050685/

Middle English Dictionary (MED): //quod.lib.umich.edu/m/med/

Oxford English Dictionary (OED): //www.oed.com/

Penn-Helsinki Parsed Corpus of Middle English, second edition (PPCME2): http://www.ling.upenn.edu/hist-corpora/PPCME22-RELEASE-3/

Penn-Helsinki Parsed Corpus of Early Modern English (PPCEME): //www.ling.upenn.edu/hist-corpora/PPCEME-RELEASE-2/

WordBanks Online (WB): //www.wordbanks.harpercollins.co.uk

\section{REFERENCES}

Adamson, Sylvia. 2000. A lovely little example: word order options and category shift in the premodifying string. In Olga Fischer, Annette Rosenbach \& Dieter Stein (eds.), Pathways of change: Grammaticalization in English, 39-66. Amsterdam: John Benjamins.

Bache, Carl \& Niels Davidsen-Nielsen. 1997. Mastering English. Berlin: Mouton de Gruyter.

Bolinger, Dwight. 1967. Adjectives in English: Attribution and predication. Lingua 18, $1-34$.

Bolinger, Dwight. 1972. Degree words. The Hague: Mouton.

Breban, Tine. 2010a. English adjectives of comparison: Lexical and grammaticalized uses. Berlin: Mouton de Gruyter. 
Breban, Tine. 2010b. Reconstructing paths of secondary grammaticalization of same from emphasizing to phoricity and single-referent-marking postdeterminer uses. Transactions of the Philological Society 108, 68-87.

Breban, Tine. 2010c. Is there a postdeterminer in the English noun phrase? Transactions of the Philological Society 108, 248-264.

Brugmann, Claudia. 1984. The very idea: A case study in polysemy and cross-lexical generalization. Chicago Linguistic Society (CLS) 20: Papers from the parasession on lexical semantics, 21-38.

Croft, William. 2000. Parts of speech as language universals and as language-particular categories. In Petra M. Vogel \& Bernard Comrie (eds.), Approaches to the typology of word classes, 65-102. Berlin: Mouton.

Davidse, Kristin. 2004. The interaction of identification and quantification in English determiners. In Michel Achard \& Suzanne Kemmer (eds.), Language, culture and mind, 507-33. Stanford: CSLI Publications.

DeLancey, Scott. 1997. Mirativity: The grammatical marking of unexpected information. Linguistic Typology 1, 33-52.

De Smet, Hendrik. 2012. Spreading patterns: Diffusional change in the English system of complementation. Oxford: Oxford University Press.

Dixon, Robert. 1982. Where have all the adjectives gone? And other essays in semantics and syntax. Berlin: Mouton.

Evans, Nicholas \& David Wilkins. 2000. In the mind's ear: The semantic extensions of perception verbs in Australian languages. Language 76, 546-92. 
Eckardt, Regine. 2012. The many careers of polarity sensitive items. In Kristin Davidse, Tine Breban, Lieselotte Brems \& Tanja Mortelmans (eds.), Grammaticalization and language change: New reflections, 299-325. Amsterdam: John Benjamins.

Ghesquière, Lobke \& Kristin Davidse. 2016. Content-purport, content-substance and structure: Focusing mere and merely. Acta Linguistica Hafniensia 48.

Gundel, Jeanette, Nancy Hedberg \& Ron Zacharski. 1993. Cognitive status and the form of referring expressions in discourse. Language 69, 274-307.

Halliday, Michael. 1963. Class in relation to the axes of chain and choice in language. Linguistics 2, 5-15.

Halliday, Michael. 1994. An introduction to Functional Grammar, 2nd edn. London: Arnold.

Halliday, Michael \& Ruquayia Hasan. 1976. Cohesion in English. London: Longman. Hopper, Paul \& Elizabeth Closs Traugott. 2003. Grammaticalization, 2nd edn. Cambridge: Cambridge University Press.

Kennedy, Christopher \& Louise McNally. 2005. Scale structure, degree modification, and the semantics of gradable predicates. Language $81,345-81$.

König, Ekkehard. 1991. The meaning of focusing particles: A comparative perspective. London: Routledge.

Langacker, Ronald. 1987. Foundations of Cognitive Grammar, vol. 1: Theoretical prerequisites. Stanford: Stanford University Press.

Langacker, Ronald. 1991. Foundations of Cognitive Grammar, vol. 2: Descriptive application. Stanford: Stanford University Press.

Langacker, Ronald. 2002. Deixis and subjectivity. In Frank Brisard (ed.), Grounding: The epistemic footing of deixis and reference, 1-27. Berlin: Mouton de Gruyter. 
Lorenz, Gunther. 2002. Really worthwhile or not really significant? A corpus-based approach to the delexicalization and grammaticalization of intensifiers. In Ilse Wischer \& Gabriele Diewald (eds.), New reflections on grammaticalization, 14362. Amsterdam: John Benjamins.

McGregor, William. 1997. Semiotic Grammar. Oxford: Clarendon.

Méndez-Naya, Belén. 2003. On intensifiers and grammaticalization: The case of swipe. English Studies 84, 372-91.

Méndez-Naya, Belén. 2006. Adjunct, modifier, discourse marker: On the various functions of right in the history of English. Folia Linguistica Historica 27, 141-69.

Nevalainen, Terttu. 1991. BUT, ONLY, JUST. Focussing adverbial change in Modern English 1500-1900. Helsinki: Société Néophilologique.

Pander Maat, Henk. 2006. Subjectification in gradable adjectives. In Angeliki Athanasiadou, Costas Canakis \& Bert Cornillie (eds.), Subjectification: Various paths to subjectivity, 279-322. Berlin: Mouton de Gruyter.

Paradis, Carita. 2000. Reinforcing adjectives: A cognitive semantic perspective on grammaticalisation. In Ricardo Bermúdez-Otero, David Denison, Richard M. Hogg \& C.B. McCully (eds.), Generative theory and corpus linguistics: A dialogue from 10 ICEHL, 233-58. Berlin: Mouton de Gruyter.

Paradis, Carita. 2001. Adjectives and boundedness, Cognitive Linguistics 12, 47-65.

Quirk, Randolph, Sidney Greenbaum, Geoffrey Leech \& Jan Svartvik. 1985. A comprehensive grammar of the English language. London: Longman.

Sinclair, John. 1991. Corpus, concordance, collocation. Oxford: Oxford University Press. 
Teyssier, Jacques. 1968. Notes on the syntax of the adjective in Modern English. Lingua $20,225-249$.

Traugott, Elizabeth Closs. 1995. Subjectification in grammaticalization. In Dieter Stein \& Susan Wright (eds.), Subjectivity and subjectivisation, 31-45. Cambridge: Cambridge University Press.

Traugott, Elizabeth Closs \& Richard Dasher. 2002. Regularity in semantic change. Cambridge: Cambridge University Press.

Traugott, Elizabeth Closs \& Ekkehard König. 1991. The semantics-pragmatics of grammaticalization revisited. In Elizabeth Closs Traugott \& Bernd Heine (eds.), Approaches to grammaticalization, vol. 1: Focus on theoretical and methodological issues, 189-218. Amsterdam: John Benjamins.

Traugott, Elizabeth Closs \& Graeme Trousdale. 2010. Gradience, gradualness and grammaticalization. How do they intersect? In Elizabeth Closs Traugott \& Graeme Trousdale (eds.), Gradualness, gradience, and grammaticalization, 19-44. Amsterdam: John Benjamins.

Vandewinkel, Sigi \& Kristin Davidse. 2008. The interlocking paths of development towards emphasizer adjective pure. Journal of Historical Pragmatics 9, 255-87. 